\title{
Growth patterns over 2 years after birth according to birth weight and length percentiles in children born preterm
}

\author{
Seulki Kim, MD, \\ Yujung Choi, MD, \\ Seonhwa Lee, MD, \\ Moon Bae Ahn, MD, \\ Shin Hee Kim, MD, \\ Won Kyung Cho, MD, \\ Kyung Soon Cho, MD, \\ Min Ho Jung, MD, \\ Byung Kyu Suh, MD
}

Department of Pediatrics, College of Medicine, The Catholic University of Korea, Seoul, Korea
Received: 12 November, 2019

Revised: 10 January, 2020

Accepted: 20 February, 2020

\section{Address for correspondence:}

Min Ho Jung, MD

Department of Pediatrics, Ajou Department of Pediatrics, The Catholic University of Korea, Yeouido St. Mary's Hospital, 62 Yeouidodong, Yeongdeungpo-gu, Seoul 07345, Korea

Tel: +82-2-3779-1131

Fax: +82-2-783-2589

E-mail:jmhpe@catholic.ac.kr

https://orcid.org/0000-0001-51887041
Purpose: To analyze growth patterns over 2 years after birth according to preterm infant birth weight and length percentiles.

Methods: Anthropometric measurements of 82 preterm infants were retrospectively reviewed. Preterm infants with birth weight or length below the 10th percentile were classified as small for gestational age (SGA) $(n=19)$ and those between the 10th and 89th percentile as appropriate for gestational age (AGA) ( $n=63)$. The association between the length standard deviation score (SDS) at 2 years of corrected age and clinical factors were analyzed.

Results: The length SDS of the SGA group was significantly increased at 6 months $(-1.30 \pm 1.71)$ and 24 months $(-0.97 \pm 1.06)$ of corrected age. The length SDS was lower in the SGA group than those in the AGA group at 6 months $(-1.30 \pm 1.71$ vs. $-0.25 \pm 1.15, P=0.004), 18$ months $(-0.97 \pm 1.39$ vs. $-0.03 \pm 1.29, P=0.015)$, and 24 months $(-0.97 \pm 1.06$ vs. $-0.29 \pm 1.12, P=0.022$,). The percentage of children with a length SDS of $<-2$ (growth failure) at 24 months was $15.8 \%$ in the SGA group and $4.8 \%$ in the AGA group ( $P=0.108$ ). Multiple linear regression analysis demonstrated that length at 24 months of corrected age was negatively correlated with birth length below the 10th percentile (coefficient $\beta=-0.91, P=0.001$ ) and duration of stay in the neonatal intensive care unit (NICU) (coefficient $\beta=-0.01, P=0.001$ ).

Conclusion: Despite the fact that catch-up growth occurs during the early period of infancy in a large portion of preterm SGA infants, a significant portion of these infants show growth failure at 24 months of age. Growth over 2 years after birth is affected by birth length and duration of stay in the NICU in preterm children.

Keywords: Prematurity, Small for gestational age, Catch-up growth

\section{Introduction}

Fetal growth is dependent on the intrauterine environment and growth at birth reflects fetal nutritional and health status, which, in turn, affects neonatal growth and health. ${ }^{1-3)}$ Consequently, neonates are classified according to gestational age, birth weight, and birth length by corrected gestational age for the evaluation of potential health and growth problems.

Premature infants are defined as those born before 37 weeks from the first day of the last menstrual period of the mother. About $4 \%-8 \%$ of all births are reported as preterm births, and preterm birth is known to be a major cause of neonatal mortality. ${ }^{4,5)}$ Preterm birth itself may be a risk factor for various complications. ${ }^{6,7)}$ Further, it places infants at a disadvantage in terms of growth and development. ${ }^{8)}$

Traditionally, small for gestational age (SGA) is defined as a birth weight below the 3rd or 10th percentile for the corresponding gestational age. Many infants born SGA have a high perinatal morbidity with a risk of short stature, obesity, and impaired neurocognitive 
development compared with infants born appropriate for gestational age (AGA). ${ }^{9,10)}$

Catch-up growth in preterm or SGA infants has been extensively studied. ${ }^{11,12)}$ However, few studies have investigated the postnatal growth patterns of infants with a birth weight in the 3rd-10th or 10th-25th percentiles. Thus, this study aimed to analyze the growth patterns of preterm infants according to birth weight and length percentiles, and to identify the factors associated with these patterns.

\section{Materials and methods}

\section{Subjects}

A total of 130 preterm infants with a gestational age of $<37$ weeks and who were admitted to the neonatal intensive care unit (NICU) of Yeouido St. Mary's Hospital, the Catholic University of Korea between January 2009 and June 2016 were enrolled. Infants with neuromuscular diseases, neonatal seizure, and intraventricular hemorrhage during follow-up were included in the study, whereas those who died during followup or exhibited severe disease, severe sequelae, or endocrine disease were excluded. After excluding 41 infants who were lost to follow-up, 4 infants with congenital hypothyroidism, 1 infant who died, 1 infant with Down syndrome, and 1 infant with cri-du-chat syndrome were excluded for a total of 82 preterm infants who were analyzed. Those with a length or weight below the 10th percentile were classified as SGA $(n=19)$, and those with a length or weight between the 10th and 89th percentile were classified as AGA $(n=63)$.

\section{Methods}

Data on length, weight, and head circumference at birth and at $6,12,18$, and 24 months of corrected age were obtained by reviewing medical charts. Length and weight were measured to $0.1 \mathrm{~cm}$ and $0.1 \mathrm{~kg}$ using a digital infant table $(\mathrm{M}-5000 \mathrm{~K}$; Nakamura Medical Industry Co., Ltd., Tokyo, Japan), and the average of 3 measurements was used. The length and weight percentiles at birth for the corresponding gestational ages were taken from the 2013 Fenton growth chart. Body mass index (BMI) was calculated using the following formula: weight $(\mathrm{kg}) /$ [height $(\mathrm{m})]^{2}$. The normative standard deviation score (SDS) for length, weight, and BMI was taken from the 2017 Korean National Growth Charts. ${ }^{13)}$

We computed the rates of length $(\mathrm{cm} / \mathrm{yr})$ and weight growth over a year $(\mathrm{kg} / \mathrm{yr})$, and analyzed the association of length SDS at 24 months of corrected age with growth rate, birth weight, gestational age, method of delivery, duration of stay in the NICU, clinical factors during NICU stay (e.g., intraventricular hemorrhage, respiratory distress syndrome, and infection), and length and weight for each age.

Growth failure was defined as a length SDS of $<-2$ at 24 months of corrected age. Catch-up growth was defined as a growth rate greater than the median for chronological age and sex for reaching a length $>-2.0$ SDS or the 3rd percentile. Normal length range was defined as a length between the $3 \mathrm{rd}$ and 97 th percentiles for chronological age and sex.

\section{Statistics}

Measurements and computed values were reported as mean \pm SD. Statistical analyses were performed using IBM SPSS Statistics ver. 20.0 software (IBM Co., Armonk, NY, USA).

The baseline measures and growth patterns for the 2 groups were analyzed using Student t-tests, and factors that affect length SDS at 24 months of corrected age were identified using multiple linear regression. The growth failure rates in the 2 groups were analyzed using the chi-square or Fisher exact tests. Statistical significance was set at $P<0.05$.

\section{Results}

\section{Subject clinical data}

There were statistically significant differences in gestational age and length at birth between the SGA and AGA groups (33.74 \pm 2.69 weeks vs. $31.72 \pm 2.97$ weeks $[P=0.010]$ and $40.35 \pm$ $5.33 \mathrm{~cm}$ vs. $43.28 \pm 4.77 \mathrm{~cm}[P=0.025]$, respectively); however, there were no differences in weight, head circumference, BMI at birth, and duration of stay in the NICU $(1.52 \pm 0.50 \mathrm{~kg}$ vs. $1.73 \pm 0.51 \mathrm{~kg}[P=0.120], 28.49 \pm 3.93 \mathrm{~cm}$ vs. $28.75 \pm 3.07 \mathrm{~cm}$ $[\mathrm{P}=0.769], 9.16 \pm 2.46 \mathrm{~kg} / \mathrm{m}^{2}$ vs. $9.18 \pm 1.69 \mathrm{~kg} / \mathrm{m}^{2}[P=0.962]$, and $37.05 \pm 26.75$ days vs. $48.38 \pm 38.70$ days $[P=0.237]$, respectively) (Table 1).

Table 1. Clinical data for $\mathbf{8 2}$ preterm infants

\begin{tabular}{lccc}
\hline Variable & SGA $(n=19)$ & AGA $(n=63)$ & $P$-value \\
\hline Gestational age $(w k)$ & $33.74 \pm 2.69$ & $31.72 \pm 2.97$ & 0.010 \\
Male sex & $7(36.8)$ & $31(49.2)$ & 0.350 \\
Measurements at birth & & & \\
Weight $(\mathrm{kg})$ & $1.52 \pm 0.50$ & $1.73 \pm 0.51$ & 0.120 \\
Length $(\mathrm{cm})$ & $40.35 \pm 5.33$ & $43.28 \pm 4.77$ & 0.025 \\
HC $(\mathrm{cm})$ & $28.49 \pm 3.93$ & $28.75 \pm 3.07$ & 0.769 \\
BMI (kg/m $\left.{ }^{2}\right)$ & $9.16 \pm 2.46$ & $9.18 \pm 1.69$ & 0.962 \\
VLBW & $8(42.1)$ & $22(34.9)$ & 0.574 \\
C-sec & $11(57.9)$ & $32(50.8)$ & 0.551 \\
Apgar score & & & \\
1 Minute & $5.26 \pm 2.38$ & $5.26 \pm 1.92$ & 0.992 \\
5 Minutes & $7.05 \pm 1.90$ & $7.26 \pm 1.48$ & 0.623 \\
$\begin{array}{l}\text { Duration of stay in NICU } \\
\text { (day) }\end{array}$ & $37.05 \pm 26.75$ & $48.38 \pm 38.70$ & 0.237 \\
Values are presented as mean & & &
\end{tabular}

Values are presented as meanıstandard deviation or number (\%). SGA, small for gestational age; AGA, appropriate for gestational age; HC, head circumference; BMI, body mass index; VLBW, very low birth weight; $\mathrm{C}-\mathrm{sec}$, cesarean section; NICU, neonatal intensive care unit. 


\section{Growth patterns over 24 months after birth}

Length SDS increased within the normal range in the SGA group, from $-1.30 \pm 1.71$ at 6 months to $-0.97 \pm 1.06$ at 24 months (Table 2). The SGA group had significantly lower length SDS at 6,18 , and 24 months $(-1.30 \pm 1.71$ vs. $-0.25 \pm 1.15[P=0.004]$, $-0.97 \pm 1.39$ vs. $-0.03 \pm 1.29[P=0.015]$, and $-0.97 \pm 1.06$ vs. $-0.29 \pm 1.12[P=0.022]$, respectively) than the AGA group (Table 2).

The weight SDS at $6,12,18$, and 24 months were lower in the SGA group than those in the AGA group $(-0.01 \pm 0.02$ vs. $0.01 \pm 0.02[P=0.001],-0.63 \pm 1.13$ vs. $0.13 \pm 1.03[P=0.009]$, $-0.89 \pm 1.09$ vs. $0.04 \pm 1.17[P=0.009]$, and $-0.87 \pm 1.11$ vs $-0.10 \pm 1.06[P=0.008]$, respectively) (Table 2 ).

The length growth rates in the SGA and AGA groups were $30.44 \pm 4.74 \mathrm{~cm} / \mathrm{yr}$ and $29.47 \pm 4.23 \mathrm{~cm} / \mathrm{yr}(P=0.415)$, respectively, in the first year after birth and $11.19 \pm 1.72 \mathrm{~cm} / \mathrm{yr}$ and $11.89 \pm 2.89$ $\mathrm{cm} / \mathrm{yr}(P=0.340)$, respectively, in the second year after birth, with no statistically significant differences (Table 2 ).

The weight growth rates in the SGA and AGA groups were $6.74 \pm 1.04 \mathrm{~kg} / \mathrm{yr}$ and $7.35 \pm 1.20 \mathrm{~kg} / \mathrm{yr}(P=0.052)$, respectively, in the first year after birth and $2.02 \pm 0.70 \mathrm{~kg} / \mathrm{yr}$ and $2.37 \pm 0.79 \mathrm{~kg} /$ yr $(P=0.096)$, respectively, in the second year after birth, also with no significant differences (Table 2).

The percentage of children with a length SDS of $<-2$ at 24 months was $15.8 \%$ in the SGA group and $4.8 \%$ in the AGA group $(P=0.108)$ (Table 2$)$. The percentage of children with growth failure decreased from $21.0 \%$ (4 of 19) at 6 months to $15.8 \%$ (3 of 19) at 24 months in the SGA group, and the

Table 2. Growth patterns of preterm infants over 2 years after birth

\begin{tabular}{lccc}
\hline Variable & SGA $(n=19)$ & AGA $(n=63)$ & $P$-value \\
\hline Length (SDS) & & & \\
6 months & $-1.30 \pm 1.71$ & $-0.25 \pm 1.15$ & 0.004 \\
12 months & $-0.59 \pm 1.28$ & $-0.26 \pm 1.95$ & 0.509 \\
18 months & $-0.97 \pm 1.39$ & $-0.03 \pm 1.29$ & 0.015 \\
24 months & $-0.97 \pm 1.06$ & $-0.29 \pm 1.12$ & 0.022 \\
Weight (SDS) & & & \\
6 months & $-0.01 \pm 0.02$ & $0.01 \pm 0.02$ & 0.001 \\
12 months & $-0.63 \pm 1.13$ & $0.13 \pm 1.03$ & 0.009 \\
18 months & $-0.89 \pm 1.09$ & $0.04 \pm 1.17$ & 0.009 \\
24 months & $-0.87 \pm 1.11$ & $-0.10 \pm 1.06$ & 0.008 \\
Length velocity $(\mathrm{cm} / \mathrm{yr})$ & & & \\
1st year & $30.44 \pm 4.74$ & $29.47 \pm 4.23$ & 0.415 \\
2nd year & $11.19 \pm 1.72$ & $11.89 \pm 2.89$ & 0.340 \\
Weight velocity $(\mathrm{kg} / \mathrm{yr})$ & & & \\
1st year & $6.74 \pm 1.04$ & $7.35 \pm 1.20$ & 0.052 \\
2nd year & $2.02 \pm 0.70$ & $2.37 \pm 0.79$ & 0.096 \\
At 24 months & & & \\
Length SDS <-2 & $3(15.8)$ & $3(4.8)$ & 0.108 \\
Length SDS <-1 & $8(42.1)$ & $12(19.0)$ & 0.041 \\
\hline Values are presented as mean \pm standard & & & \\
\hline
\end{tabular}

Values are presented as mean \pm standard deviation or number (\%). SGA, small for gestational age; AGA, appropriate for gestational age; SDS, standard deviation score. percentage of children with growth failure was $6.3 \%$ (4 of 63) at 6 months and $4.8 \%$ (3 of 63) at 24 months in the AGA group.

\section{Correlation analysis for length SDS at 24 months of corrected age and relevant factors}

Correlation analysis showed that length SDS at 24 months was significantly positively correlated with length at birth $(r=0.27, P=0.016)$ (Table 3$)$, length growth rates in the first and second years after birth $(r=0.21, P=0.001$ and $r=0.54, P=0.001$, respectively) (Table 3 ), and weight growth rates in the first and second years after birth $(r=0.59, P=0.001$ and $r=0.61, P=0.001$, respectively) (Table 3 ). Gestational age was not significantly correlated with length SDS at 24 months of corrected age $(r=0.06, P=0.610)$ (Table 3). Multiple linear regression showed that length SDS at 24 months of corrected age was negatively correlated with birth length below 10th percentile (coefficient $\beta=-0.91, P=0.001$ ) (Table 4 ) and duration of stay in the NICU (coefficient $\beta=-0.01, P=0.001$ ) (Table 4 ). Length SDS at 24 months of corrected age was positively associated with length growth rates in the first and second years after birth (coefficient $\beta=0.08, P=0.002$ and coefficient $\beta=0.13, P=0.001$, respectively), and with weight growth rates in the first and second years after birth (coefficient $\beta=0.23, P=0.004$ and coefficient $\beta=0.35$,

Table 3. Association of clinical factors with length standard deviation score at $\mathbf{2 4}$ months of corrected age

\begin{tabular}{|c|c|c|}
\hline \multirow[t]{2}{*}{ Variable } & \multicolumn{2}{|c|}{$\begin{array}{l}\text { Length SDS at } 24 \text { months of } \\
\text { corrected age }\end{array}$} \\
\hline & Correlation coefficient $(r)$ & $P$-value \\
\hline Gestational age (wk) & 0.06 & 0.610 \\
\hline Length at birth (cm) & 0.27 & 0.016 \\
\hline Weight at birth (kg) & 0.21 & 0.060 \\
\hline Length SDS at 12 months & 0.28 & 0.013 \\
\hline Weight SDS at 12 months & 0.67 & 0.001 \\
\hline Weight SDS at 24 months & 0.78 & 0.001 \\
\hline 1st year length velocity (cm/yr) & 0.21 & 0.001 \\
\hline 2 nd year length velocity $(\mathrm{cm} / \mathrm{yr})$ & 0.54 & 0.001 \\
\hline 1st year weight velocity (kg/yr) & 0.59 & 0.001 \\
\hline 2nd year weight velocity (kg/yr) & 0.61 & 0.001 \\
\hline
\end{tabular}

SDS, standard deviation score.

Table 4. Multiple linear regression analysis of factors affecting length standard deviation score at $\mathbf{2 4}$ months of corrected age

\begin{tabular}{lccc}
\hline Variable & Coefficient $\beta$ & SE & $P$-value \\
\hline Length <10th percentile at birth & -0.91 & 0.74 & 0.001 \\
Weight <10th percentile at birth & -0.21 & 0.212 & 0.330 \\
Duration of stay in the NICU & -0.01 & 0.003 & 0.001 \\
Length velocity (cm/yr) & & & \\
1st year & 0.08 & 0.025 & 0.002 \\
2nd year & 0.13 & 0.031 & 0.001 \\
Weight velocity (kg/yr) & & & \\
1st year & 0.23 & 0.078 & 0.004 \\
2nd year & 0.35 & 0.111 & 0.003 \\
\hline
\end{tabular}

SE, standard error; NICU, neonatal intensive care unit. 
$P=0.003$, respectively) (Table 4 ).

\section{Discussion}

The impact of SGA birth on infant growth patterns and final height as adults has been extensively studied. However, few studies have focused on preterm infants alone. Although the sample size is not large, this study, which compared the growth patterns of preterm SGA and AGA infants, provides important details and expands the current knowledge on preterm infant growth.

About $84 \%$ of the preterm SGA infants in this study achieved catch-up growth at 24 months of corrected age. Most of the children who achieved catch-up growth entered the normal length range for their corrected age within the first 6 months after birth. This is consistent with previous findings that early postnatal growth is crucial for catch-up growth. ${ }^{12,14,15)}$ However, despite reaching the normal height range, these children were still in the lower normal range, which has a potential association with the high prevalence of short stature as adults among SGA infants. ${ }^{13,15-17)}$ Meanwhile, about $15 \%$ of the preterm SGA infants remained below -2.0 length SDS at 24 months of corrected age.

We found a positive correlation between length SDS at 24 months and birth length. Multiple linear regression analysis showed that length SDS at 24 months is negatively correlated with birth length below the 10th percentile. These results suggest that catch-up growth in early childhood is more closely related to small length than weight or gestational age at birth. Most studies used birth weight percentile as a criterion for assessing catch-up growth among SGA infants ${ }^{18-20)}$; however, our results showed that birth length percentile may be a more important factor in evaluating growth in height. ${ }^{21)}$ Therefore, it is important to consider length when defining, following up, and evaluating SGA infant prognosis.

In addition, length SDS at 24 months was negatively correlated with duration of stay in the NICU, suggesting that early postnatal catch-up growth is influenced not only by postnatal complications by themselves but also by environmental factors such as postnatal care including nutritional supplements or medication.

Postnatal growth is divided into the infancy, childhood, and adolescent periods, and growth failure in any of these periods increases the possibility of short stature in adulthood. ${ }^{22,23)}$ Growth in early childhood, particularly during the 24 months after birth, has an impact on growth in later childhood and puberty, ${ }^{24)}$ ultimately leading to final adult height. In this study, 3 of 63 preterm AGA infants (4.8\%) had growth failure at 24 months. Two infants underwent partial colectomy owing to necrotizing colitis, and one extremely low birth weight infant developed bronchopulmonary dysplasia after the neonatal period and had recurrent episodes of bronchiolitis. These data support previous results showing that growth failure in early infancy is associated not only with potential risk in the fetal period $^{1-3)}$ which causes prematurity and/or SGA, but also with postnatal conditions. ${ }^{25-28)}$
Compared with full-term infants, infants born preterm encounter various problems during their growth, ${ }^{28)}$ and even preterm AGA infants may be at risk of growth failure. Hence, investigation and clinical consideration of the factors contributing to growth failure are important, especially in infants born preterm. Although the postnatal growth rate of a preterm infant vastly differs from the fetal growth rate, most evaluations of preterm infant growth have been based on fetal growth, and a recent study revealed that such growth evaluation in preterm infants is inappropriate. ${ }^{2,29)}$ Thus, growth evaluation should be based on growth data obtained by analysis of the growth patterns of preterm infants separately from that of fullterm infants. Such an evaluation may be helpful for determining the timing and method of intervention to promote the health, growth, and development in society of preterm infants.

SGA infants are at a high risk of short stature as adults if they fail to achieve catch-up growth. Additionally, even SGA infants who achieve catch-up growth have an increased risk of developing metabolic syndrome, including obesity, diabetes, and hypertension. ${ }^{10,30)}$ Therefore, the desirable period and degree of catch-up growth that lead to the best growth outcome and health status as adults should be meticulously analyzed in future studies.

This study has some limitations. Firstly, its small size from a single center might affect statistical significance. Secondly, this study could not take parents' height and disease history into account because of the nature of the retrospective chart reviews, and could not consider environmental factors that may have affected growth, such as nutritional status after NICU discharge. More systematic studies, such as a prospective study, are needed, considering that various diseases associated with premature birth may affect postnatal growth. Furthermore, comparing growth patterns of infants born preterm with those of infants born at term during the same study period could enhance the robustness of this data.

In conclusion, despite the fact that the catch-up growth occurs during early period of infancy in a large portion of preterm SGA infants, a significant portion of these infants has growth failure at 24 months of age. Growth over 2 years after birth is affected by birth length and duration of stay in the NICU in children born preterm. Because growth occurs over a long period that encompasses infancy, childhood, and puberty, it is important to follow up the growth of preterm infants beyond infancy until adulthood.

\section{Ethical statement}

This study was approved by the Institutional Review Board of Catholic Medical Center (SC18RESI0071).

\section{Conflict of interest}

No potential conflict of interest relevant to this article was reported. 


\section{References}

1 Niklasson A, Engstrom E, Hard AL, Hellstrom A. Growth in very preterm children: a longitudinal study. Pediatr Res 2003;54:899-905.

2. Giuliani F, Cheikh Ismail L, Bertino E, Bhutta ZA, Ohuma EO, Rovelli I, et al. Monitoring postnatal growth of preterm infants: present and future. Am J Clin Nutr 2016;103:635S-647S.

3. Fenton TR, Kim JH. A systemic review and meta-analysis to revise the Fenton growth chart for preterm infants. BMC Pediatr 2013;13:59.

4. Liu L, Johnson HL, Cousens S, Perin J, Scott S, Lawn JE, et al. Global, regional, and national causes of child mortality: an updated systematic analysis for 2010 with time trends since 2000. Lancet 2012;379:2151-61.

5. Blencowe H, Cousens S, Oestergaard MZ, Chou D, Moller AB, Narwal R, et al. National, regional, and worldwide estimates of preterm birth rate in the tear 2010 with time trends since 1990 for selected countries : a systematic analysis and impliation. Lancet 2012;379:2162-72.

6. Parkinson JR, Hyde MJ, Gale C, Santhkumaram S, Modi N. Preterm birth and the metabolic syndrome in adult life: a systematic analysis and meta-analysis. Pediatrics 2013;131:1240-63.

7. Sultton PS, Darmastadt GL. Preterm birth and neurodeveloment:a review of outcomes and recommendations for early identification and cost-effective intervention. J Trop Pediatr 2013;59:258-65.

8. Clark RH, Olsen IE, Spitzer AR. Assessment of neonatal growth in prematurely born infants. Clin Perinatol 2014;41:295-307.

9. Clayton PE, Cianfarani S, Czernichow P, Johannsson G, Rapaport R, Rogol A. Management of the children born small for gestational age through to adulthood: a consensus statement of the International Societies of Pediatric Endocrninology and the Growth Hormone Research Society. J Clin Endocrinol Metab 2007;92:804-10.

10. Taine M, Charles MA, Beltrand J, Roze JC, Leger J, Botton J, et al. Early postnatal growth and neurodevelopment in children born moderately preterm or small for gestational age at term: A systematic review. Paediatr Perinat Epidemiol 2018;32:268-80.

11. Karlberg J, Albertsson-Wikland K. Growth in full-term small for gestational age infants: from birth to final height. Pediactr Res 1995;38:733-9.

12. Itabashi K, Mishina J, Tada H, Sakurai M, Nanri Y, Hirohata Y. Longitudinal follow-up of height up to five years of age in infants born preterm small for gestational age; comparison to full-term small for gestational age infants. Early Hum Dev 2007;83:327-33.

13. Korea Centers for Disease Control and Prevention, Division of Choronic Disease Surveillance, Committee for the Development of Growth Standard for Korean Children and Adolescents; Korean Pediatric Society, Committee for School Health and Public Health Statistics. 2017 Korean children and adolescents growth standard. Cheongju (Korea): Korea Centers for Disease Control and Prevention, Division of Chronic Disease Surveillance, 2017.

14. Chen S, Liu Z, Zhu H, Yang H, Gong F, Wang L, et al. Height at three months can indicate overweight at two years in catch-up growth of small for gestational age infants. Sci Rep 2018;8:13411.

15. Cho WK, Suh BK. Catch-up growth and catch-up fat in children born small for gestational age. Korean J Pediatr 2016;59:1-7.

16. Karberg J, Albertsson-Wikland K, Kwan CW, Chan FY. Early spontaneous catch-up growth. J Pediatrc Endocrinol Metab 2002;15:1243-55.

17. Hokken-Koelega AC, De Ridder MA, Lemmen RJ, Den Hartog H, De Muinck Keizer-Schrama SM, Drop SL. Children born small for gestational age: do they catch up? Pediatr Res 1995;38:267-71.

18. Westwood M, Kramer MS, Munz D, Lovett JM, Watters GV. Growth and development of full-term nonasphyxiated small-for-gestational age newborns: follow-up through adolescence. Pediatrics 1983;71:376-82.

19. Tenovuo A, Kero P, Piekkala P, Korvenranta H, Sillanpaa M, Erkkola R. Growth of 519 small for gestational infants during the first two years of life. Acta Paediatr 1987;76:63646.

20. Fitzhardinge PM, Inwood S. Long-term growth in smallfor-date children. Acta Paediatr 1989;349:27-33.

21. Botero D, Lifshitz F. Intrauterine growth retardation and long-term effects on growth. Curr Opin Pediatr 1999;11:340-7.

22. Ng SM, Pintus D, Turner MA. Extreme premature small for gestational age infants have appropriate catch-up growth at term equivalence compared with extreme premature appropriate for gestational age infants. J Clin Res Pediatr Endocrinol 2019;11:104-8.

23. Albertsson-Wikland K, Karlberg J. Natural growth in children born SGA with and without catch up growth. Horm Res 2003;59 Suppl 1:129.

24. Zhang L, Li Y, Liang S, Liu XJ, Kang FL, Li GM. Postnatal length and weight growth velocities according to Fenton reference and their associated perinatal factors in healthy late preterm infants during birth to term-corrected age: an observational study. Ital J Pediatr 2019;45:1.

25. FentonTR, Nasser R, Eliasziw M, Kim JH, Bilan D, Sauve R. Validating the weight gain of preterm infants between the reference growth curve of the fetus and the term infant. BMC Pediatr 2013;13:92.

26. Sauer PJ. Can extrauterine growth approximate intrauterine growth? Should it? Am J Clin Nutr 2007;85:608-13.

27. Villar J, Giuliani F, Bhutta ZA, Bertino E, Ohuma EO, Ismail LC, et al. Postnatal growth standards for preterm infants: the preterm postnatal follow-up study of the INTERGROWTH-21(st) project. Lancet Glob Health 
2015;3:681-91.

28. Saenger P, Czernichow P, Hughes I, Reiter EO. Small for gestational age: short stature and beyond. Endocr Rev 2007;28:219-51.

29. Cormack BE, Embleton ND, van Goudoever JB, Hay WW Jr, Bloomfield FH. Comparing apples with apples :it is time for standardized reporting of neonatal nutrition and growth studies. Pediatr Res 2016;79:810-20.

30. Stevens A, Bonshek C, Watmore A, Butcher I, Hanson D, De Leonibus $C$, et al. Insights into the pathophysiology of catch-up compared with non-catch-up growth in children born small for gestational age: an integrated analysis of metabolic and transcriptomic data. Pharmarcogenomics J 2014;14:376-84. 